\title{
A CONSTRUÇÃO DO CONHECIMENTO SOCIOAMBIENTAL NA GESTÃO DO ESPAÇO RURAL: O CASO DE DERRUBADAS - RS
}

\author{
THE CONSTRUCTION OF KNOWLEDGE \\ SOCIOENVIRONMENTAL IN SPACE MANAGEMENT RURAL: \\ THE CASE OF DERRUBADAS - RS
}

\author{
Dhonathã Santo Rigo \\ Universidade Federal de Santa Maria - Santa Maria - RS - Brasil \\ Pedro Selvino Neumann \\ Universidade Federal de Santa Maria - Santa Maria - RS - Brasil \\ Paulo Roberto Cardoso da Silveira \\ Universidade Federal de Santa Maria - Santa Maria - RS - Brasil
}

\begin{abstract}
Resumo: A inadequada ocupação de áreas rurais e a intensa exploração dos recursos naturais caracterizadas pelo uso conflitivo do solo, bem como, pelo processo de alienação educacional e produtivo ao qual a população rural é submetida, aprofunda problemas socioambientais já identificados ao final do século passado. O trabalho se propõe a estudar a realidade complexa da zona rural do Município de Derrubadas, como um esforço de construção de conhecimento e análise, identificando o design paisagístico e sob a diversidade dos fatores naturais e sociais presentes, zonas relativamente homogêneas e as especificidades socioambientais presentes em uma delas. Na realização do estudo, foram utilizados procedimentos metodológicos e técnicas apropriadas para abordagens qualitativa e quantitativa. Fez-se o uso da análise dos dados secundários, leitura da paisagem, entrevista com informantes qualificados e com a comunidade envolvida, além da construção de mapas temáticos utilizando o software spring e da análise físicoquímica de amostras de água. Como resultado, evidenciou-se a forma desigual de ocupação do espaço rural do município, com grande concentração de sua população em áreas rurais fragilizadas, de baixa aptidão para uso agrícola, limitada do ponto de vista produtivo e fundiária. Para a comunidade estudada, a aposentadoria e o beneficio assistencial (bolsa família) estão presentes na renda de $75 \%$ das famílias entrevistadas. Do resultado da análise de água, praticamente todas as fontes se mantiveram fora dos padrões de potabilidade estabelecidos pelo Ministério da Saúde, principalmente pela presença de coliformes totais e fecais. Esses resultados estão fortemente relacionados às condições sociais encontradas para a comunidade, onde $42 \%$ das famílias não possuem banheiro interno e, em $50 \%$ das casas, os dejetos são destinados a céu aberto. Aliado a essa variável, a falta de planejamento paisagístico ambiental das áreas, principalmente de região de nascentes, contribuem para agravar os níveis de contaminação encontrados e evidencia a problemática socioambiental de tal comunidade.
\end{abstract}

Palavras-chave: Diagnostico dos Sistemas Agrários. Conhecimento Socioambiental. Unidade de Conservação.

Abstract: Inadequate occupation of rural areas and the intense exploitation of natural resources characterized by conflicting land use, as well as the divestiture process educational and productive rural population which is subjected, deepens social problems already identified at the end of the last century. The paper aims to study the complex reality of the rural municipality of Derrubadas, as an effort to build knowledge and analysis, identifying the landscaping design in the diversity of natural and social factors present, relatively homogeneous areas and the aspects socioenvironmental gifts in one of them. In the study we used methodological procedures and 
techniques for qualitative and quantitative approaches. Was done using the analysis of secondary data, reading the landscape, interviewing qualified informants and the community involved, besides the construction of thematic maps using the software spring and physical-chemical analysis of water samples. As a result, is observed the uneven occupation of rural areas of the county, with a large concentration of its population in vulnerable rural areas, low in suitability for agricultural use, limited in terms of production and land. For the community studied, retirement and welfare benefit (family bag) are present in income of $75 \%$ of the families interviewed. The result of water analysis, virtually all sources remained outside the potability standards established by the Ministry of Health, particularly the presence of total and fecal coliforms. These results are strongly related to social conditions encountered in the community, where $42 \%$ of households do not have an indoor bathroom and $50 \%$ of the houses, waste products are designed the-sky-opened. Allied to this variable, the lack of environmental planning of areas, mainly springs region, contributing to worsening levels of contamination found and highlights the environmental problems of such a community.

Keywords: Diagnostic analysis of agrarian systems. Socioenvironmental knowledge. Conservation unit.

\section{INTRODUÇÃO}

A inadequada ocupação de áreas rurais e a intensa exploração dos recursos naturais caracterizadas pelo uso conflitivo do solo, bem como, pelo processo de alienação educacional e produtivo ao qual a população rural é submetida, realimentam os sistemas produtivos inadequados em relação à aptidão do ambiente e aprofunda problemas socioambientais identificados já ao final do século passado, tais como: a escassez qualitativa de água, a diminuição da produtividade, a poluição do ambiente, a redução da biodiversidade e o empobrecimento sociocultural da população rural.

Sob esse prisma, a observação da matriz produtiva agropecuária do Município de Derrubadas, centrada na produção de soja e de grãos para exportação, produzida por agricultores familiares de posse de pequenas áreas, faz enquadrar a região em baixos níveis de desenvolvimento e o município entre os de menores índices de crescimento econômico do Estado do Rio Grande do Sul ${ }^{1}$.

Identifica-se, para o município, uma grande parcela da população ainda no campo, mas com reflexos evidentes e dinâmicos de êxodo rural e urbanização. A migração ocorre primeiro para as cidades da região e, na grande carência de empregos nestas, passa-se a migrar para centros maiores, o que vem causando uma diminuição da população rural e total dos municípios da região. Segundo Trennepohl e Macagnan (2008), os grandes problemas da região, na atualidade, podem ser resumidos nos seguintes itens: empobrecimento relativo da região; pressão dos sistemas produtivos sobre os recursos naturais; crescente perda de dinamismo da economia regional, empobrecimento social decorrente das dificuldades da inserção da agricultura familiar no mercado e as precárias condições de moradia de parcela significativa da população, com deficiências de saneamento básico e outros meios a garantir melhores condições de vida. Como

\footnotetext{
1 Seu Produto Interno Bruto - PIB decresceu 5,68\% entre os anos de 2001 e 2005, caindo da 374a posição para a $391^{\text {a }}$ no ranking estadual do índice (IBGE, 2006).
} 
consequência dos fatores elencados, advém a baixa capacidade de absorção da mão de obra e retenção da população, gerando êxodo rural e emigração regional.

Cientes que todas as atividades humanas produzem impactos sobre o meio ambiente, cuja magnitude e intensidade dependem do tipo de atividade e características dos ecossistemas analisados, os dados oficiais sobre a contenção do ritmo de degradação ambiental que foram identificados em anos anteriores para a região, principalmente no que se refere às formações vegetais que se encontram associadas aos corpos d'água e sobre os níveis de contaminação por produtos químicos ou minerais derivados das atividades agrícolas, tornam-se, hoje, ultrapassados e ineficientes para avaliar a situação ecológica do município.

Mesmo abrigando um dos maiores e mais importantes parques florestais do Rio Grande do Sul (Parque Estadual do Turvo), preservando várias espécies florestais e animais da fauna brasileira ameaçadas de extinção, o restante de seu espaço rural, mais de 17 mil hectares, reproduz uma agricultura convencional e que tende a comprometer os recursos naturais e a permanência dos agricultores no meio rural.

Nesse sentido, este trabalho pretende dar uma pequena contribuição ao estudar a realidade complexa da zona rural do Município de Derrubadas, como um esforço de construção de conhecimento e análise. O trabalho constituiu-se de várias etapas efetivas do geral ao específico, proporcionando a reconstrução da história agrária da região, identificando o design paisagístico-ambiental formado pela história pregressa da ocupação do espaço agrário, além de compreender, identificar e classificar, sob a diversidade dos fatores naturais e sociais presentes, zonas relativamente homogêneas e as especificidades socioambientais presente em uma delas.

\section{MÉTODO EMPREGADO E CONSIDERAÇÕES SOBRE O ESTUDO DE CASO EM DERRUBADAS}

Para a elaboração do trabalho, foram utilizados procedimentos metodológicos e técnicas de pesquisa, quer sejam de natureza qualitativa ou quantitativa. A base de dados sobre a qual se apoiam as análises realizadas é composta por informações obtidas mediante pesquisa de campo e por dados secundários extraídos de fontes censitárias. O trabalho situa-se como um estudo de caso, opção devido à premência de tempo. As condições financeiras disponíveis e o grau de abrangência pretendido exigem um tipo de pesquisa mais rápida, mas não menos rigorosa.

A Investigação foi conduzida com base na etapa inicial da Análise Diagnóstico dos Sistemas Agrários (DUFUMIER, 1996; GARCIA FILHO, 2001; MAZOYER e ROUDART, 2001), a qual permite a compreensão das formas de uso do espaço rural, por meio do conhecimento das articulações entre a base geo-biofísica e as atividades humanas sobre ela desenvolvidas, inseridas em um contexto macroeconômico e político-institucional. 
O trabalho foi realizado em base a uma análise geral para a específica, segundo a concepção metodológica utilizada, onde parte-se da compreensão da ocupação do espaço do município e região, onde desenvolvem-se, no decorrer do tempo, diferentes sistemas de produção que alteram a base geo-bio-física e avança-se para a análise de como estas alterações passam a ser condicionados em sua evolução, interagindo com as práticas agrícolas adotadas, influenciadas por determinadas opções tecnológicas e políticas.

Como produto desta primeira etapa, obteve-se a definição de zonas relativamente homogêneas, segundo suas características físicas (edáficas, microclimáticas e topográficas) e características socioeconômicas (demográficas, estrutura fundiária, infraestrutura rural, tipo de ocupação do espaço rural, serviços públicos, atividades agrícolas etc).

Em um segundo momento investigativo, buscar-se-á compreender, em nível mais aprofundado, uma zona dito homogênea, sendo esta a base formadora do artigo, identificando o sistema de produção e os conflitos entre as dimensões econômicas e ambientais presentes.

\subsection{Procedimentos Metodológicos}

Em um primeiro momento, objetivando conhecer a evolução do sistema agrário no município, foram utilizadas técnicas de pesquisa como:

- Análise de Dados Secundários: visando conhecer as características agroecológicas e socioeconômicas do município, via mapas de uso do solo, imagens e fotos aéreas disponíveis, estudos já realizados sobre o município e as informações disponíveis nos órgão oficiais de pesquisa;

- Análise da Paisagem: buscando conhecer as formas de ocupação do espaço rural foi realizado um reconhecimento do terreno, identificando, pela paisagem, a forma como tem sido utilizado e transformado o espaço rural, as diferentes atividades produtivas e os recursos naturais disponíveis;

- Entrevistas com Informantes Qualificados: para reconstituir a evolução do uso do espaço agrário do município, fizeram-se necessárias entrevistas com agricultores idosos, lideranças e um técnico que atuam na área;

- Elaboração de mapas temáticos: Para análise da cobertura vegetal, utilizase imagens temáticas de satélites da série Landsat, trabalhadas em software. A base cartográfica usada para elaboração dos mapas temáticos foi construída a partir de folhas topográficas editadas pelo Instituto Brasileiro de Geografia e Estatística-IBGE, escala 1:100.000, e pelo mapa do Município de Derrubadas via Google Earth. Utilizou-se como equipamentos um Microcomputador; GPS de navegação e o software spring.

O Sistema de Processamento de Informações Geográficas-Spring é um Sistema de Informações Geográficas-SIG no estado-da-arte com funções de processamento de imagens, análise espacial, modelagem numérica de terreno e consulta a bancos de dados espaciais. (INPE, 2009). 
No segundo momento da pesquisa, buscou-se identificar zonas relativamente homogêneas e, para definir a tipologia dos sistemas de produção, valeu-se das entrevistas aos agricultores e profissionais que atuam no meio rural. Foram frequentes, na pesquisa, reuniões com as diferentes instituições municipais, tais como: a Secretaria do Turismo, Secretaria de Agricultura e Meio Ambiente, Secretaria de Assistência Social e Emater, além da participação de sete reuniões nas diferentes comunidades rurais do município.

A partir de um conjunto de definições e informações, partiu-se para a seleção e posterior aprofundamento das relações socioambientais existentes em uma das zonas, esta definida, por sua forte especificidade natural e pela dimensão socioeconômica. Nessa etapa, aplica-se amostragem dirigida, abrangendo a diversidade de produtores na zona, perfazendo treze entrevistas a campo, junto aos agricultores familiares, juntamente com a identificação dos recursos hídricos da comunidade, com posterior análise de água, a fim de relacionar as práticas agrícolas adotadas pelos agricultores e a influência das mesmas sobre as condições ambientais.

O instrumento de coleta de dados foi organizado de maneira semiestruturada com 25 questões abertas e fechadas e dividido em quatro blocos. O primeiro bloco do questionário refere-se à caracterização e perfil da família (perguntas 1.1 a 1.3). O nome dos membros entrevistados foi solicitado, no entanto, esclareceu-se que não seria utilizado na redação do relatório, visando preservar as pessoas quanto às informações cedidas. $O$ segundo bloco de questões direciona-se à busca de informações sobre a Unidade de Produção Familiar, a caracterizar o uso da área e utilização do solo, produção vegetal e animal, descrição da tipologia do sistema agrícola e uso ou não de práticas conservacionistas (perguntas 2.1 a 7.0). O terceiro bloco aborda aspectos seguradores da qualidade de vida da população rural, como acesso à saúde pública, à educação, à moradia, à energia elétrica, ao abastecimento de água, entre outros (perguntas 8.0 a 8.1). O quarto e último bloco referem-se ao relacionamento dos moradores com o território do Parque Estadual do Turvo (perguntas 9.1 a 9.10), abordando aspectos de informação ambiental, conhecimento relativo dos entrevistados sobre o território da Unidade de Conservação e perguntas multicategóricas sobre a gestão e restrições impostas pelo plano de manejo do Parque.

A qualidade da água das fontes de abastecimento doméstico das propriedades rurais, nascentes e córregos, foram avaliados mediante os parâmetros descritos por Rheinheimer, et al. (2008).

\section{RELATO DO ESTUDO DE CASO E DISCUSSÃO}

\subsection{Aspectos Agroecológicos do Município}

Buscando compreender as dimensões ambientais do município e sua relação com a estrutura social, atualmente distribuída espacialmente no território, 
desenvolvem-se alguns mapas temáticos usados como ferramenta para sobreposição de dados, bem como a construção e armazenamento de informações em uma plataforma digital de fácil leitura e operação.

Segue, na Figura 1, a confecção de um mapa de base cartográfica, extraindo os limites do território via IBGE e sobrepondo quatro cartas cartográficas. Obtém-se um mapa temático com usos múltiplos, permitindo o reconhecimento físico e espacial do território, a caracterização e localização das comunidades, além de ser utilizado como um instrumento guia para as entrevistas de campo e análise da paisagem e posterior cruzamento de informações.

Figura 1. Imagem das cartas cartográficas que delimitam o Município de Derrubadas, RS

Fonte: http://w3.ufsm.br/geografia/cartografia/cartatopografica/html/

Observa-se, por meio da Figura 1, que a estrutura do município, delimitada pela linha amarela contínua, configura-se por um relevo fortemente ondulado, subentendido pela proximidade entre as curvas de níveis, ou seja, quanto mais próximas, maior a declividade em porcentagem em uma dada distância.

Por abrigar em seu território uma Unidade de Conservação Integral de esfera estadual, com aproximadamente 18.000 hectares, proibindo qualquer tipo de alienação, arrendamento ou ônus, bem como exploração agrícola ou industrial (área destacada em verde escuro na figura 1), o município garante a proteção e manutenção de uma das maiores áreas de mata atlântica do Estado do Rio Grande do Sul, preservando várias espécies da fauna e flora brasileira ameaçadas de extinção. O restante da vegetação atual que cobre o município é praticamente toda de uma sucessão de culturas anuais de inverno e verão, e que será melhor 
descrita pelas entrevistas com os agricultores e extensionistas rurais. Ocasionalmente, restam fragmentos isolados de uma mata nativa exuberante preservada apenas em pequenas áreas.

Os mapas temáticos (Figura 2 e 3) são construídos sobre imagem de satélites da série Landsat, trabalhados em softwares Spring. Esse software é disponibilizado pelo Instituto Nacional de Pesquisa Espacial-INPE, com funções de processamento de imagens, análise espacial, modelagem numérica de terreno e consulta a bancos de dados espaciais ${ }^{2}$.

Figura 2. Mapa Temático do uso da Terra, Município de Derrubadas, RS, 2009

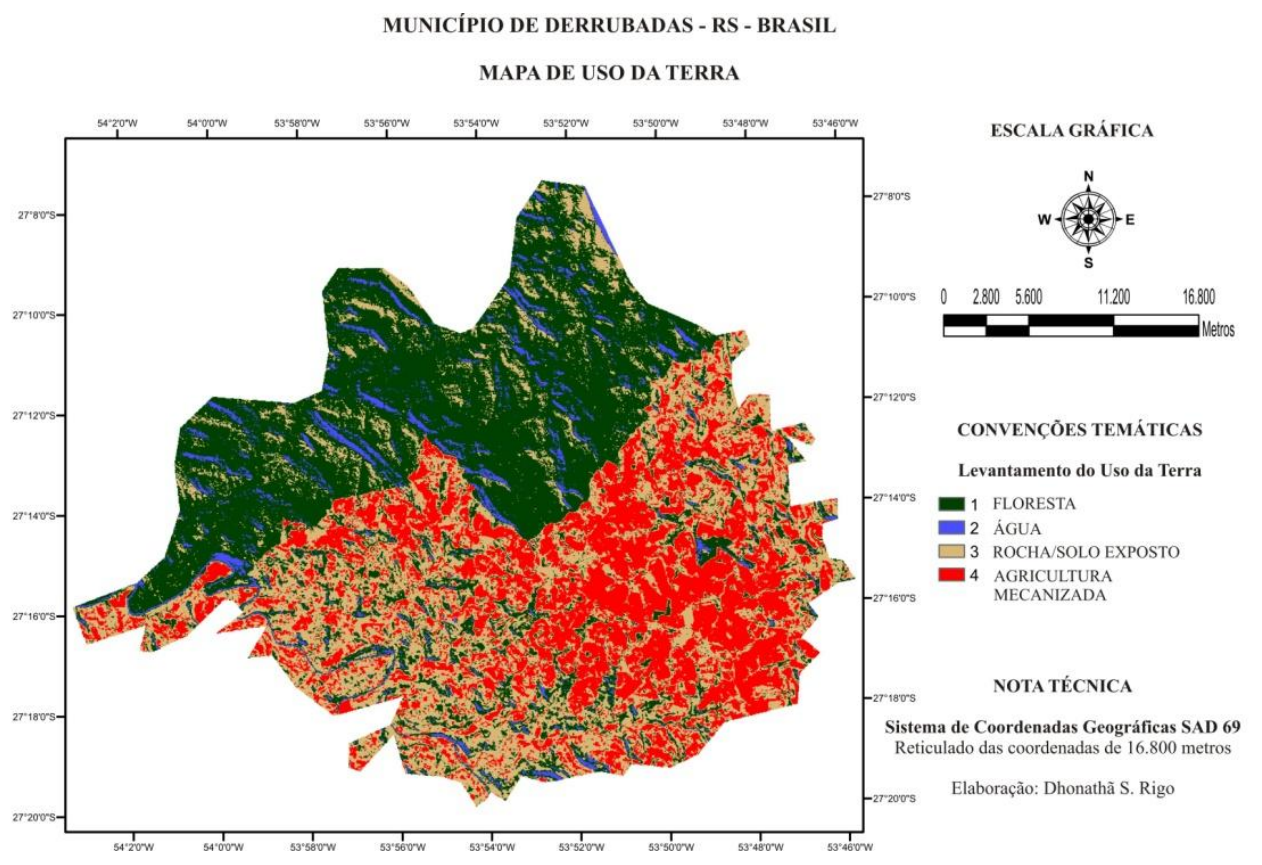

Fonte: Elaborado pelo autor com base nas imagens Landsat do município de Derrubadas, RS. Escala 1:560.000.

Observa-se, para o mapa de uso da terra (Figura 2), que a área de cobertura vegetal considerada como de mata e/ou floresta representa $46,87 \%$ (19.080,60 ha) do total da área do município. No entanto, ao retirarmos a área do Parque Estadual, a soma da área "verde" baixa para 8,7\% (3.538,71 ha), representadas sobre pequenas áreas isoladas, localizadas em fundo de vales e rincões de alta declividade.

Ainda sobre a Figura 2, identifica-se, para o território, um montante de 10237,95 hectares de área mecanizada (área em vermelho). O mesmo valor é encontrado para a área de solo exposto (área em bege) ou área com alto grau de declividade acompanhada por afloramento de rocha, o que, segundo as entrevistas

\footnotetext{
${ }^{2}$ Consultado em http://www.dpi.inpe.br/spring/. Através do site, aquisição do programa e cursos de curta duração para operacionalização do software.
} 
com técnicos e agricultores, é atribuído ao uso de culturas anuais de verão (soja e milho) e de inverno (trigo e aveia).

A partir do bando de dados sobre o município, foi construído o mapa de declividade (Figura 3) o qual tem sido considerado um documento básico para os planejadores regionais, com múltiplas utilizações para os estudos da estrutura agrária e da geomorfologia. Esse mapa permitirá visualizar a distribuição da população no espaço, correlacionando a declividade e o acesso a áreas com melhor aptidão agrícola.

O mapa de declividade foi elaborado automaticamente, a partir de um modelo digital de elevação, gerado usando-se as folhas, com equidistância entre as curvas de nível de 50 metros. Distinções baseadas nessas condicionantes são empregadas para prover informações sobre praticabilidade de emprego de equipamentos agrícolas, normalmente os mecanizados, e facultar inferências sobre susceptibilidade dos solos à erosão.

Baseado nas declividades críticas para determinado tipo de uso da terra, foram mapeadas as seguintes classes de declividade: menor do que $2 \%$ (relevo plano), 2 a $5 \%$ (relevo suave ondulado), 5 a $10 \%$ (relevo medianamente ondulado), 10 a $15 \%$ (relevo ondulado) e maior do que $15 \%$ (relevo fortemente ondulado), conforme Figura 3 no mapa de declividade.

Figura 3. Mapa de declividade, Município de Derrubadas, RS

MUNICÍPIO DE DERRUBADAS - RS - BRASIL

MAPA DE DECLIVIDADE
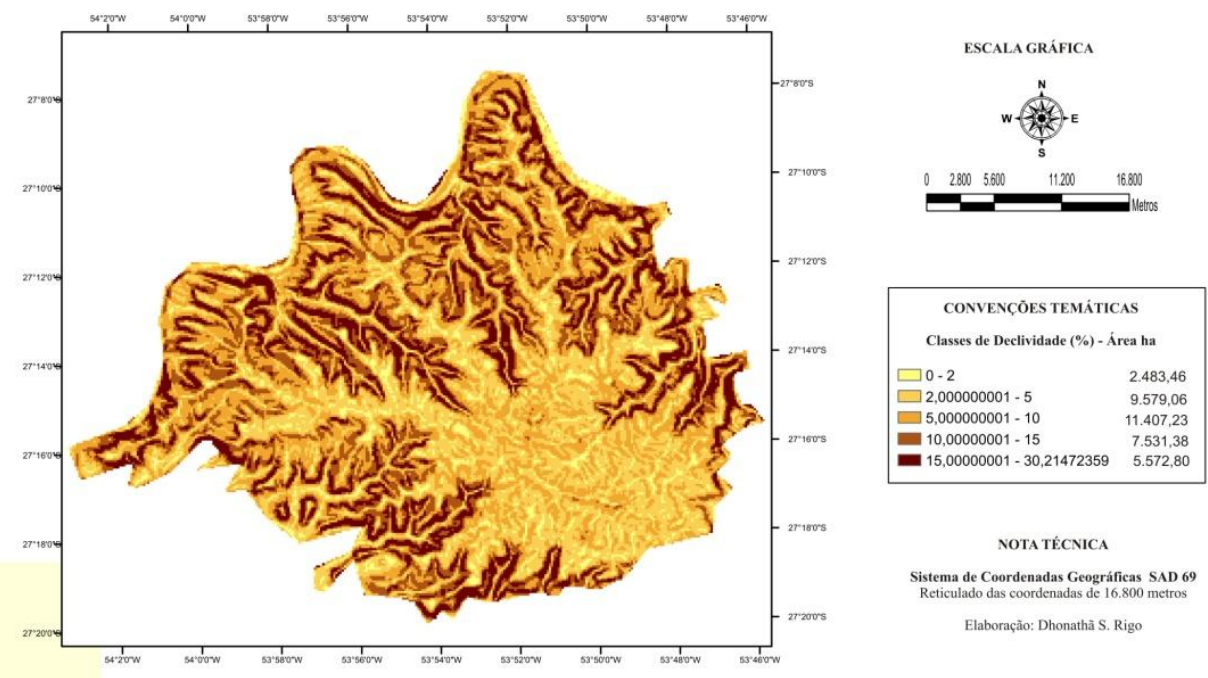

Fonte: Elaborado pelo autor com base nas imagens Landsat do município de Derrubadas, RS. Escala 1:560.000. 
Pela análise da figura 3, verifica-se que a maior parte do município $(71,39$ $\%$ da área) apresenta declividade maior do que 5\%, e aproximadamente $40 \%$ da área apresenta declividade acima de 10\%. Ao sobrepor a estrutura fundiária do município sobre a estrutura do mapa, nota-se que a distribuição espacial das propriedades no território, principalmente a das propriedades familiares de produção ${ }^{3}$, encontra-se nas áreas marginais de maior declividade e com fortes restrições físicas para produção agrícola. Consequentemente, a grande fração da população municipal, disposta nos espaços rurais, localiza-se nas áreas tipificadas acima.

\subsection{Transcrição da análise de paisagem e entrevistas com informantes chaves}

A análise da paisagem foi composta por algumas expedições (percursos sistemáticos de campo) realizada no município, com o objetivo de identificar as formas de exploração e do manejo do meio ambiente, seus diferentes tipos de agricultura e os condicionantes ecológicos das atividades agrícolas. Os elementos norteadores dessa etapa usados para identificar as especificidades de cada conjunto de agricultores ou da localidade no espaço geográfico foram as práticas agrícolas adotadas, a intensificação do uso do solo, a estrutura fundiária e as atividades executadas no meio rural.

As entrevistas foram realizadas individualmente com alguns técnicos extensionistas e valendo-se de reuniões coletivas de grupos de agricultores, organizadas pela Cooperativa Mista Yucumã ${ }^{4}$ (setor de laticínio), que mantém reuniões mensais com todos os grupos (num total de 240 associados), distribuídos, em sua maioria, por zonas ou localidades.

Mediante percorrida em todas as localidades do município e via os procedimentos supracitados, observou-se, dentre os sistemas produtivos, a paisagem modelada pela produção de monoculturas anuais de verão e inverno, tanto em áreas de baixa declividade como em pequenas áreas com relevo acentuado, por meio de práticas tradicionais de manejo, tais como aração com tração animal e capina manual.

\footnotetext{
${ }^{3}$ De acordo com o IBGE (2006), 85\% das propriedades são consideradas familiares (das 887 propriedades existentes).

${ }^{4}$ A cooperativa reúne em grande proporção minifundiários produtores de leite, excluídos do processo convencional de produção, dado a baixa produtividade e volume produzido e que encontraram no cooperativismo uma forma de manter-se no sistema produtivo, reduzindo os riscos da flutuação de preço de mercado, e criando até certo grau de barganha na compra e venda de insumos. A associação dos produtores de leite nasceu com a organização técnica do funcionário da EMATER/ Derrubadas e técnicos da Secretaria de Agricultura e Meio Ambiente do município.
} 
Estes procedimentos, acrescidos às consultas internas, tornam visíveis dois sistemas macro de produção, disposto em um formato " $U$ " sobre o mapa temático de uso da terra. Um sistema produtivo familiar, com ênfase na produção de leite, identificado nas extremidades do município, partindo do lado oeste em divisa com o Município de Três Passos, ligado pela parte norte contígua ao Parque Estadual do Turvo e propriedades ao leste com divisa aos municípios de Barra do Guarita e Tenente Portela. Associa-se a esse grupo agricultores com forte restrição de área e por estas estarem sob declividade fortemente acidentada, concentrando a maioria da população rural do município.

O outro sistema produtivo familiar é característico da região central, que envolve a cidade. Enquadra áreas mais planas sob cotas mais elevadas, com menos restrições físicas e mecânicas, reunindo produtores familiares de pequenas e médias propriedades, dando ênfase à produção de grãos, associado à criação de animais para ordenha, sendo, essa última relegada a segundo plano, como retrata o técnico agrícola da prefeitura.

[...] a grande maioria da população, tá mesmo, é na pirambeira, e com muita dificuldade tentam sobreviver com as vaquinhas de leite que é a principal atividade.

Para esses dois sistemas, atribuem-se subsistemas produtivos que, posteriormente, serão descritos no decorrer do trabalho. No entanto, identificamse, sob a Tabela 1, algumas informações úteis para percepção das diferentes localidades no plano do território e a identificação desses dois sistemas produtivos no interior das comunidades, tanto ao centro quanto nas extremidades do município.

A avaliação por localidade, neste caso, torna-se um instrumento importante para o levantamento de informações qualitativas a respeito do modo de reprodução dos atores sociais, uma vez que o objeto de estudo tende a escolher uma zona relativamente homogênea ou uma comunidade ou bacia hidrográfica representativa de um sistema macro de produção. 
Tabela 1. Descrição da estrutura fundiária, $n^{\circ}$ de produtores, variação da área em hectares, total de ha por localidade, área dobrada, mecanizada, de mato e inaproveitada, por localidade

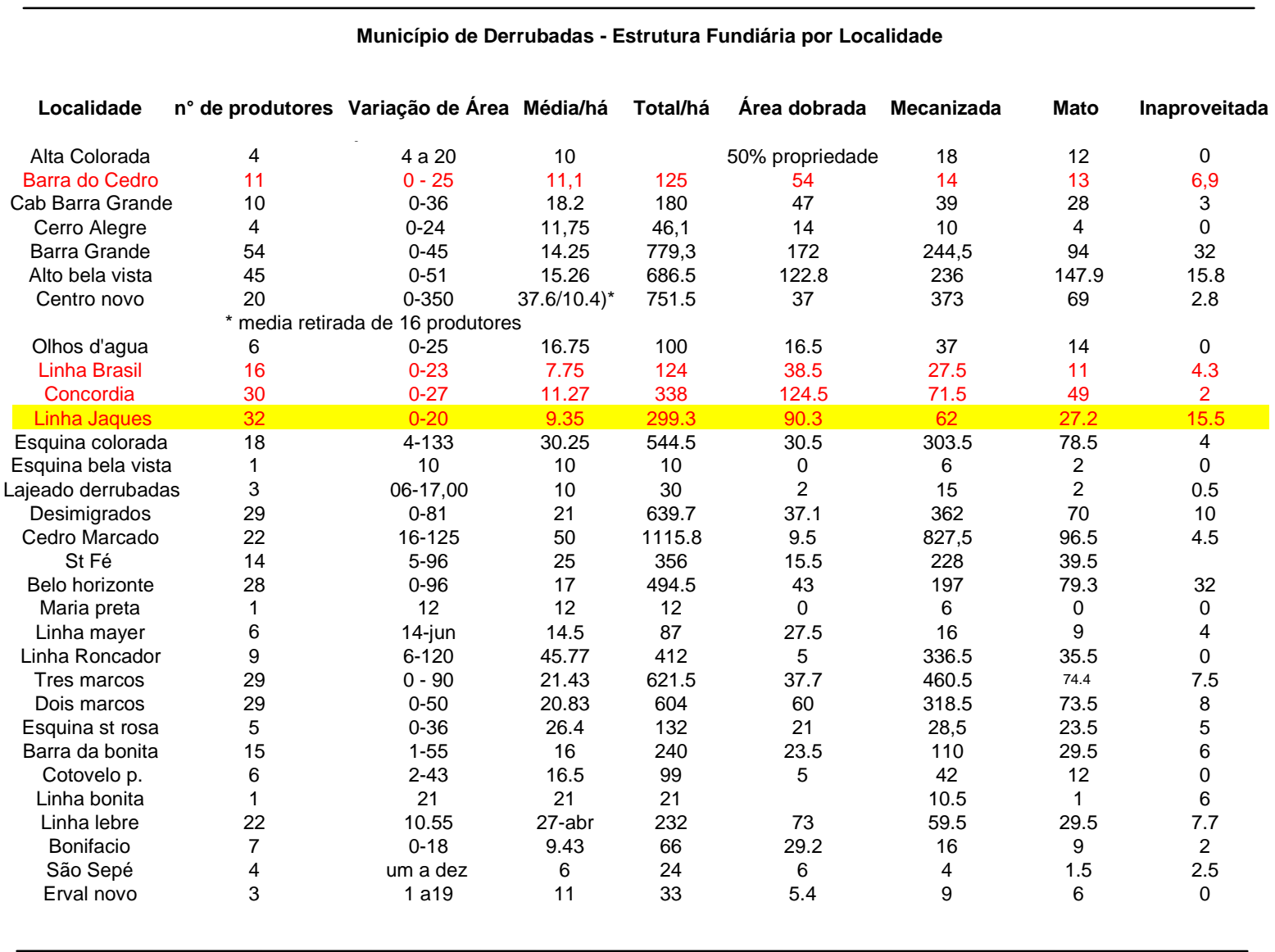

Fonte: elaborada pelo autor a partir dos dados internos da secretaria da agricultura cruzadas com entrevistas coletivas nas comunidades.

Por meio da Tabela 1, obtém-se uma fotografia das diferentes comunidades existentes no município, referenciando o número de famílias por comunidade, a posse e a quantidade de área fracionada em área de declividade, mecanizada, entre outras. O estudo permitiu identificar subsistemas de produção colocados em prática pelos agricultores familiares, os quais se reproduzem em todas as distintas comunidades, exceto para uma única comunidade que apresenta produção de fumo.

Sistema Produtivo 1: Área de Agricultores familiares com ênfase na produção de grãos

Sistema representado por médios produtores que se dedicam à produção de soja milho e trigo, além de pequenos proprietários presentes nas extremidades do município que buscam no arrendamento uma ampliação da renda para compensar a baixa remuneração por área dessas culturas. Esses produtores possuem assistência técnica privada, com plena aceitação ao uso de tecnologias ditas "modernas", advindas pela utilização de máquinas e implementos agrícolas e, na 
sua maioria, praticantes de um sistema "quimificado" de produção, com alta utilização de agrotóxicos.

Sistema Produtivo 2: Área de Agricultores familiares com ênfase na produção de leite e outras culturas

Com base na combinação das atividades agropecuárias das propriedades, esse sistema se subdivide em três categorias de produtores.

a) Agricultores familiares com ênfase na produção de leite e grãos.

Agricultores familiares que dispõem de área suficiente para suportar o rebanho leiteiro e que insistem em manter a produção de grãos para exportação, por estar presente nos pilares culturais de seus ascendentes ou por não dispor de unidades de trabalho familiar para aumentar a atividade principal. Podem atribuir as propriedades de integração lavoura - pecuária, e/ou propriedade de produção de milho para silagem em grãos e de pé inteiro.

b) Agricultores familiares com ênfase na produção de subsistência.

Categoria de agricultores excluídos das trocas mercantis de produtos primários por não dispor de área e força de trabalho suficiente. Representa vários agricultores aposentados residentes no meio rural, pessoas sem terra, agregados sem renda, e que sobrevivem com auxílios governamentais como bolsa família. As atividades de subsistência (milho, feijão, horta, horta doméstica, bovinos, aves e suínos) destinam-se unicamente ao consumo da família.

c) Agricultores familiares produtores de fumo

Apenas alguns membros de uma comunidade (Barra Grande) praticam essa atividade. As áreas disponíveis são reduzidas (a maioria dispõe de menos de cinco hectares) e possuem uma infraestrutura mínima para a cultura do fumo: moradia, estufa com varanda, galpão, tecedeira e prensa de fumo. O nível de equipamento é baixo, sendo composto, basicamente, de equipamentos de tração animal, ferramentas manuais e animais de serviço. A mão de obra é quase exclusivamente familiar e absorvida em sua totalidade pelas atividades agrícolas, ocorrendo, raramente, a realização de atividades não agrícolas. Os sistemas de cultivos implementados por esses agricultores estão fortemente estruturados em torno dos "pacotes tecnológicos" impostos pela indústria fumageira. Além da fragilidade dos vínculos legais com a terra, a implementação dessa tecnologia, fundamentada no uso intensivo de insumos químicos, consolida a situação de dependência desses agricultores para com a indústria.

\section{AGRICULTURA FAMILIAR COM ÊNFASE NA PRODUÇÃO DE LEITE: UMA VISÃO DETALHADA DA LINHA JAQUES}

A comunidade da Linha Jaques localiza-se ao lado oeste do Município de Derrubadas, perfazendo divisa com o Município de Três Passos, limite dado pelo 
rio Turvo e pelo Parque Estadual do Turvo. Fica a uma distância aproximadamente de $15 \mathrm{~km}$ da sede do município por estrada não asfaltada.

A localidade reflete as características citadas para o sistema de produção com base na atividade leiteira, possuindo categorias de produtores restritos à produção de alimentos para autoconsumo e alguns poucos da associação leite e grãos. Os motivos que levaram a escolha dessa comunidade para o aprofundamento de informações qualitativas ocorreu pelo interesse de analisar e entender os dados disponíveis sobre a comunidade, e que estão frisados na Tabela 1, e por carregar uma especificidade, que é ser contígua ao Parque Estadual do Turvo e de um dos mais importantes rios da região (rio Turvo).

A comunidade é formada por 30 famílias de agricultores distribuídas em 299,3 há. Apresenta declividade acentuada em grande maioria das terras cultivadas e a posse da terra pelos produtores familiares dá-se como atributo de pertencimento e modo de vida, ao estarem acima de 30 anos na localidade. Pela análise da paisagem, toma-se para a comunidade os atributos que se identifica em todas as comunidades da "extremidade" do município. No entanto, apresenta-se com uma estrutura fundiária menor que a média do município e com alguns indicadores socioambientais únicos, como por ser uma das comunidades do interior que mais é assistida pelos auxílios assistenciais do governo federal como o Bolsa Família.

Pelos indicadores ambientais disponibilizados pela Secretaria da Saúde do município, ao sobrepor os laudos de 73 amostras (distribuídos espacialmente no território municipal, incluído água de poço artesiano e fontes drenadas) analisadas em 2006, observou-se que 26,03\% apresentaram Coliformes Totais e 73,97\% indicam que a água não atende os parâmetros de Coliformes Totais, Coliformes Termotolerantes (coliformes fecais) e contagem de Bactérias Heterotróficas estabelecida pela portaria do Ministério da Saúde, sendo água imprópria para o consumo caso não seja feito algum tipo de tratamento. Para o ano de 2008, os dados apontam que, das 47 amostras, 51\% apresentam coliformes Totais e 38,13\% coliformes Totais e Fecais. Para 2009, das 13 análises realizadas, todas apresentaram coliformes totais e em três, coliformes Totais e Fecais (as três presentes na localidade da L. Jaques).

O sistema de abastecimento de água para as famílias da comunidade ocorre via encanamento e distribuição de quatro fontes drenadas e protegidas, realizada pela Emater e prefeitura em anos anteriores, e por um poço artesiano advindo de outra comunidade. E justamente esses pontos de coleta, mesmo com certo grau de proteção, apresentam, desde 2006, contaminações por Coliformes Totais, Coliformes Termotolerantes (coliformes fecais) e contagem de Bactérias Heterotróficas estabelecida pela portaria do Ministério da Saúde.

Mediante tais indicadores, busca-se, por meio das entrevistas semi estruturadas, organizadas na forma de um questionário com 25 perguntas abertas e fechadas, aplicadas de forma não aleatória, reconhecer o processo histórico das famílias, os aspectos relativos aos fatores que regem a qualidade de vida, a dinâmica produtiva e sua relação com a Unidade de Conservação (Parque Estadual do Turvo). 


\subsection{Resultados da Amostra Dirigida}

A entrevista foi dirigida a 13 famílias da comunidade, buscando compreender a diversidade de produtores e de sistemas de produção existentes. A escolha das famílias foi orientada e acompanhada pela agente de saúde da comunidade, que foi baseada na representatividade dos moradores e sua distribuição no território. Elaborou-se um cadastro prévio de todas as famílias da comunidade, com informações sobre o tamanho da área, área útil, atividades agrícolas executadas e componentes familiares. Outro ponto importante para a escolha dessas famílias, foi a relação de três moradores por fonte de abastecimento de água, uma vez que será relacionado às atividades produtivas e sua influência na qualidade da água.

Nota-se, que o grau de escolaridade de todas as famílias entrevistadas não ultrapassa a $5^{\circ}$ serie e $15 \%$ deles nunca frequentaram a escola, argumentando as dificuldades da época de acesso e permanência. Em relação à condição de posse de área, a variação identificada vai de agregados (camponeses pobres estabelecidos em terras alheias), arrendatários, proprietários de um hectare, até famílias trabalhando de maneira coletiva em propriedade com 50 ha, (pais, com três filhos casados). Dentre as famílias entrevistadas, $75 \%$ delas recebem outra fonte de rendimento, principalmente aposentadoria e Bolsa Família.

Todos os agricultores que exploram áreas com pastagem cultivada, fazem sob plantio direto e uso de fertilizantes químicos e orgânicos. Na avaliação da área, essa atividade não ultrapassa cinco ha até em propriedades maiores. Assim, o restante sustenta mata nativa (por motivo da declividade) ou pastagem natural sem uso de melhoramento de espécies e da fertilidade do campo.

Das propriedades analisadas $83 \%$ trabalham com produção de leite a pasto, com uma média de cinco a dez vacas em lactação e todas apresentam criação de suínos e horta doméstica para autoconsumo. Apenas $41 \%$ dos agricultores acessam o PRONAF e $100 \%$ destes financiamentos é direcionado para cultura como soja, milho e trigo.

As perguntas relacionadas ao terceiro bloco, que envolvem os fatores sobre qualidade de vida, demonstram que $100 \%$ das moradias dos agricultores são de madeira, mais de $95 \%$ delas acima de 30 anos e a metade acima de 50 anos, porém, com desgaste, mais razoavelmente em boas condições de habitabilidade.

O abastecimento d'água usado na casa onde reside a família é via fonte drenada de uso coletivo, localizada nas cotas mais altas da comunidade e todas as propriedades dispõem de energia elétrica, atendimento médico e odontológico e educação da rede municipal.

Para $42 \%$ das propriedades, o tipo de sanitário usado na residência é do tipo "patente", casinha localizada externamente à residência. Em relação ao destino dos dejetos da casa onde reside a família, 50\% são destinados a céu aberto (lançado no potreiro e "perau"), o restante, destinado em fossa negra, tipo sumidouro, localizado próximos da casa e córrego. O lixo orgânico tem destinação 
para reciclagem natural em horta ou criação de animais em $100 \%$ das propriedades entrevistadas.

Em relação à pergunta 8.8, que instiga os agricultores a identificar os principais problemas da comunidade, seja de natureza ambiental social e/ou econômico, apenas uma família reconhece que, "[...] aqui agente sofre com a poluição ambiental, com o descarte de lixo no rio, sempre desce embalagem de agrotóxico quando chove muito e não dá para esquecer da pobreza, né![...]", demonstrando para muitos entrevistados a dificuldade de problematizar os acontecimentos concretos da realidade e sua necessidade de mudança.

Para o último bloco de perguntas, buscando compreender a relação da comunidade e dos atores sociais com a Unidade de Conservação-UC a qual são lindeiros, aplica-se 12 questões multicategórica, abordando os benefícios ou não, de ser vizinho de uma UC, o conhecimento sobre o Parque e sua gestão e percepção dos agricultores sobre o plano de manejo, entre outras.

Para $62 \%$ das famílias, o Parque Estadual não traz nenhum benefício para si ou para comunidade, porém, os restantes enfatizam que há um beneficio ambiental para toda região. Na sequência, 100\% afirmam não haver prejuízo por serem vizinhos do Parque. Esses dados se apresentam de maneira similar ao encontrado em um estudo descrito no plano de manejo da unidade direcionado a outras comunidades, que não encontra nenhuma vantagem econômica por ser contíguos ao Parque $(90,5 \%)$ e que deveria haver algum benefício aos proprietários de áreas vicinais $(63,5 \%)$.

Quando questionados sobre o gestor da UC, a grande maioria não conhece em primeiro momento. Porém, quando citado o nome, por se tratar de um biólogo natural do município, sua relação com o mesmo é caracterizada como boa por 100 \% dos entrevistados. Em mesma proporção, ao perguntar sobre a gestão da unidade, $25 \%$ dos entrevistados classifica como boa e $75 \%$ não sabem ou classifica como ruim a gestão da unidade. Para $100 \%$ da população, o relacionamento da comunidade com o Parque Estadual se dá de forma passiva e sem conflitos.

Frente à pergunta 9.6, quando questionados sobre o plano de manejo da unidade, $100 \%$ não conhecia ou nunca obteve informações dos gestores do Parque ou de instâncias responsáveis. Ao pedir qual o nível de conhecimento sobre a área de amortecimento, a grande maioria (70\%) não tem conhecimento, os restantes ouviram no rádio, porém, não sabem a área delimitada.

Quando perguntados sobre quais as atividades proibidas e permitidas na área de amortecimento, 33\% deles afirmam que é proibido uso de espécies transgênicas e de agrotóxicos. Para 100\% das famílias, a área da comunidade não faz parte da área de amortecimento do UC. E 67\% não têm nenhuma informação sobre a pergunta, mas há comentários por parte de uma família que, “[...] deveria ser proibido passar veneno nessa área".

Não há qualquer dúvida, entretanto, por parte dos vizinhos, quanto ao destino que deve ser dado ao Parque: 100\% entende que este deve ser 
preservado, "[...] sendo muito importante para todo Estado e por ser a única forma de preservação" (frase dita por muitos entrevistados).

No conteúdo da pergunta 9.10, que abre para sugestões ou críticas direcionado ao Parque Estadual do Turvo, surgem as principais menções:

\footnotetext{
"[...] O governo deveria dar mais atenção ao Parque, sei lá, a infraestrutura do parque tá precária, nem existe, eu acho[...]".

"[...] Não fica nada para o município, nem a entrada dos turistas," tem que mudar muito[...]"

"[...] Tá bom, sempre foi assim [...]"

"[...] Tá bom, desde que não me prejudique [...]"

"[...] Falta estrutura para o turista, atividade de turismo rural além do Salto Yucumã, que venham pros morros, vê como é bonito [...]"

"[...] Eu acho que tem que ter alguma forma de compensar com dinheiro as propriedades vizinhas [...]"
}

Ao perguntar, sob livre escolha, se gostariam ou não de ser vizinhos do Parque, 25\% admitiram que não queriam. O restante é indiferente, desde que não os prejudique, foi o argumento usado por muitos entrevistados.

\subsection{Qualidade da água e a relação com a dinâmica produtiva da comunidade}

De posse da realidade vivenciada na comunidade e dos dados já disponíveis sobre a evolução da situação de algumas fontes protegidas de uso coletivo, faz-se necessária uma avaliação mais detalhada dos recursos hídricos que envolvem o espaço rural e as interferências provocadas pelas práticas agrícolas sobre equilíbrio natural. A mensuração da qualidade da água ou seu monitoramento previne o aparecimento de várias doenças no homem e nos animais e auxilia o diagnóstico das principais formas de contaminação.

Segundo Rheinheimer (2003), as principais interferências de grande impacto no meio rural se configuram pela agressão às áreas de vegetação permanentes, à utilização de agrotóxicos e fertilizantes, à má destinação dos dejetos animais e humanos e aos resíduos de produtos industrializados. Todos esses contaminantes são carreados pela água com as partículas de solo ou são depositados diretamente nos mananciais.

Como a paisagem da bacia hidrográfica que envolve a comunidade é caracterizada pela alta declividade, seguida pela exposição de rocha para a maioria das áreas de lavoura, o que, para Rheinheimer et al. (2003), potencializa o escorrimento superficial e a geração de sulcos profundos e voçorocas quando não corretamente manejadas, tornando-se uma preocupação constante, já que tende a comprometer a manutenção do sistema produtivo utilizado pelos produtores, bem como a influenciar a saúde coletiva da comunidade.

Por outro lado, embora a comunidade apresente uma área com vegetação natural preservada acima da média do município, é constatada a falta de proteção (mata ciliar) ao longo dos córregos que afloram na cabeceira da bacia e nos topos 
de morro acima das nascentes, possivelmente explicada pela pressão fundiária e pela pouca presença de áreas com aptidão para os cultivos agrícolas. Para Copetti, et al. (2009), a mata ciliar auxilia a ciclagem de elementos químicos e substâncias orgânicas nas margens dos corpos d'água, o que garante uma menor contaminação dos poluentes difusos.

Como as fontes coletivas enquadram-se como área de cabeceiras, dando origem às nascentes de rios, a garantia da conservação da qualidade da água superficial dependerá da proteção e do nível de interferência nas áreas de encostas e topos sobre as nascentes. Nesse sentido, compreender a importância e a influência dessas quatro fontes (que abastecem as 30 famílias) para a seguridade de um dos pilares constitucionais dos direitos humanos é o objeto de interesse desse tópico e a proposição de alternativas torna-se fundamental.

\subsubsection{Descrição e caracterização dos pontos de coleta}

Como descrito, a comunidade dispõe de quatro fontes drenadas e a contribuição de uma linha estendida do poço semi artesiano da comunidade vizinha para satisfazer as 30 famílias da localidade, bem como, usos isolados por parte de moradores de reservatórios próprios e captação de pequenas nascentes a jusante das fontes coletivas localizadas na área de cabeceira da bacia.

Foram coletadas treze amostras em distintos pontos no município. Os dois primeiros para efeito de comparação. O primeiro coletado no interior do Parque Estadual do Turvo, em uma nascente exposta e utilizada para abastecimento da sede do Parque, com livre circulação de animais silvestre como antas, guaxinins e onça pintada. O segundo ponto na saída de um córrego com nascentes no interior do centro urbano da cidade de Derrubadas, feito para avaliar o impacto do vilarejo no arroio, uma vez que é drenado para dentro da UC.

O terceiro ponto de coleta localizado no início da comunidade da Linha Jaques, coordenadas geográfica $27^{\circ} 15^{\prime} 33.56^{\prime \prime} \mathrm{S}-53^{\circ} 57^{\prime} 41.51^{\prime \prime} \mathrm{O}$, avalia uma fonte drenada de uso coletivo, abastecendo oito famílias a jusante, com um fluxo da fonte para uma caixa central e desta, para as moradias. A fonte encontra-se sobre um capão de mato, precariamente cercada por fios de arame farpados, entremeio a lavouras mecanizadas de soja (a cima) e potreiro (sobre e abaixo), não impedindo a entrada de animais. No quarto ponto (Jaques 02), a fonte situa-se no interior de uma área extremamente preservada, coordenadas geográficas $27^{\circ} 15^{\prime} 35.62^{\prime \prime} \mathrm{S}-53^{\circ} 57^{\prime} 49.61^{\prime \prime} \mathrm{O}$, sem acesso a animais de sangue quente. No entanto, recebe a contribuição de uma grande área agrícola mecanizada, localizada acima da mata. A amostra foi coletada na torneira de uma propriedade, pela dificuldade de acesso à fonte, que, redistribui, a partir da caixa coletiva, para oito casas a jusante.

O ponto $\mathrm{n}^{\circ} 5$ coletado na fonte Laste 01/ Manfroi abastece a propriedade do produtor e de três vizinhos. A fonte encontra-se às margens do Parque Estadual do Turvo, na meia encosta, logo abaixo da estrada, sendo o divisor de água. Acima da fonte, a área de contribuição é toda ela de uma área extensa de 
binômio soja - trigo mecanizado. Poucos metros abaixo, um capão de mato que se interliga à reserva florestal do Parque. A água é bombeada por uma bomba submersa. A amostra foi coletada na casa de um dos moradores beneficiados.

O ponto 6 , fonte drenada Laste 02 , abastece nove famílias a jusante da fonte localizada entre a lavoura mecanizada (acima), com uma área significativa de contribuição por apresentar uma cota superior, e abaixo, um potreiro para gado de leite, oferecendo uma pressão constante sobre a fonte, pois se interliga à área de banhado sobre o potreiro e o local da fonte. A distribuição é por diferença de declividade até uma caixa coletiva e daí sua distribuição às famílias. A coleta foi realizada na casa de um agricultor abaixo do sistema. A fonte localiza-se na propriedade do agricultor Celso Laste que utiliza água de outro poço desprotegido acima da fonte drenada (ponto de coleta 8 deu-se na casa do agricultor).

O sétimo ponto coletado apresenta-se sobre as coordenadas geográficas $27^{\circ} 15^{\prime} 44.02^{\prime \prime} \mathrm{S}-53^{\circ} 58^{\prime} 15.71^{\prime \prime} \mathrm{O}$, no meio de um potreiro, sem isolamento para os animais, alicerçado com paredes de tijolos sem proteção superior, ficando a poucos metros do açude e em mesma cota da estrada. Essa fonte abastece somente uma família. A água foi coletada na casa do agricultor.

A água coletada na posição 9, refere-se a um corpo d'água formado por nascentes que sustentam duas das fontes anteriormente descritas. O ponto de coleta localiza-se no final da comunidade, perfazendo aproximadamente $2 \mathrm{~km}$ das nascentes ao ponto coletado, próximo às casas, escola e a 50 metros de um cemitério localizado na meia encosta de um morro.

Observa-se que as margens do córrego recém formado (Figura 4) encontram-se totalmente desprotegidas, sem matas ciliares e com pressões de várias naturezas, seja pela falta de vegetação e pela proximidade das áreas agrícolas, bem como, pela inexistência de coleta e tratamento dos esgotos domésticos lançados, na maioria das vezes, diretamente no córrego, ou pela infiltração de patentes e sumidouro situados às margens do rio, causando interferência direta no aumento do fluxo em períodos de cheias e pela própria infiltração no interior do solo.

Figura 4. Margens do arroio originado na comunidade, linha Jaques, Derrubadas, RS, Brasil
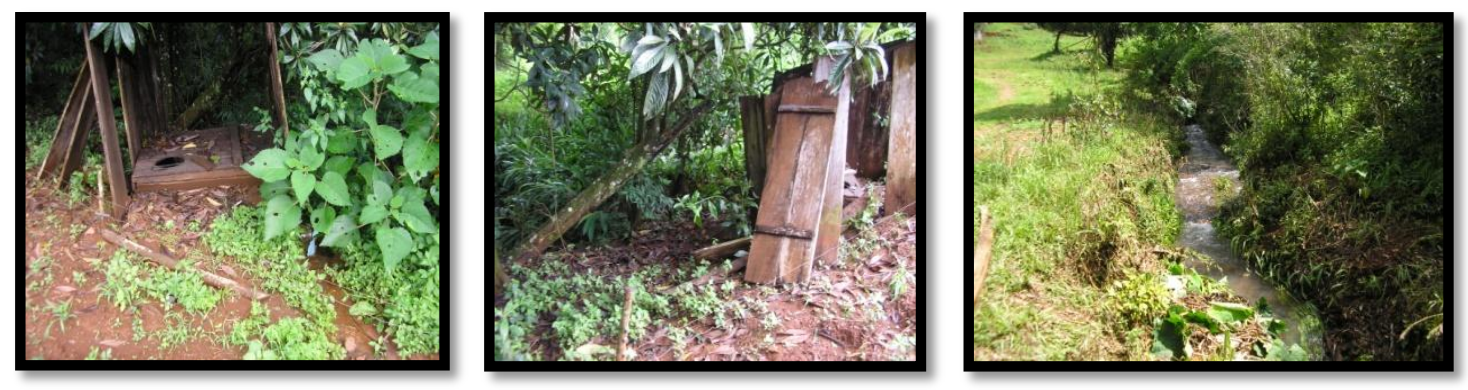

O ponto de coleta da amostra $\mathrm{n}^{\circ} 10$ e 11 , foi retirado da propriedade do agricultor Sírio Simão, próximo à sanga Jaques, pois o agricultor consome água do 
poço semiartesiano, Barra Grande (amostra 10) e de uma fonte localizada no interior do potreiro, alegando que a água do poço artesiano contém muito fluoreto.

A fonte, em meio ao potreiro, encontra-se próximo a uma esterqueira desativada, contendo material orgânico em seu interior. É alicerçada com paredes de tijolos, porém, totalmente desprotegida na parte superior, estando acessível a dessedentação animal. A amostra foi coletada diretamente na fonte.

Figura 5. Coleta $n^{\circ}$ 11(Sírio Simão) para analise da qualidade da água, fonte sobre uma esterqueira
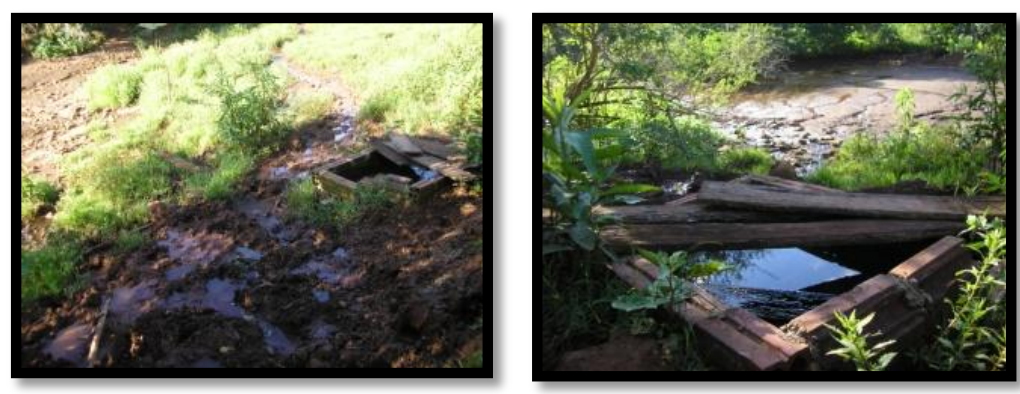

O último ponto coletado localiza-se em outro córrego formado pelas nascentes de cabeceira usadas para consumo e citadas na parte superior do trabalho. O ponto de coleta encontra-se no final do território da bacia e tende a refletir as contradições praticadas nos seus três km que se estende a montante até sua origem.

Ao logo do percurso do rio, acima do ponto coletado, naturalizam-se pelos agricultores as práticas executadas de longa data, que podem comprometer a qualidade deste recurso. Em vários momentos, identifica-se embalagens vazias de agrotóxicos nas proximidades de ambos os córregos, depositadas em áreas alagadas pela elevação do nível do riacho, além de material orgânico derivado de criações próximas e fossas humanas.

Os riachos, em muitos trechos, cortam as estradas de circulação de veículos e animais pela falta de bueiros, o que aumenta o risco de acidentes com a população rural e contaminação externa. Nota-se, também, uma grande contribuição das estradas para adição de sedimentos nos rios, facilitado pela drenagem lateral que conduz a água e pela falta de mata ciliar a impedir sua infiltração.

\subsubsection{Interpretação dos parâmetros microbiológico, organoléptico e físico- químico}

As coletas, tanto para a análise microbiológica como para o monitoramento dos parâmetros físico-químicos, seguem os procedimentos preconizados pela 
legislação e exigidos pelo Laboratório de Análise de Águas Rurais-LAAR, do Centro de Ciências Rurais da UFSM.

Os parâmetros físicos, químicos e biológicos da água foram examinados por meio das seguintes variáveis: $\mathrm{pH}$, condutividade elétrica, cálcio total, magnésio total, ferro total, dureza total, amônia, nitrato, turbidez, cor aparente, sólidos dissolvidos totais, coliformes fecais e coliformes totais. As análises foram coletadas no dia 19 de novembro e encaminhadas ao laboratório nove horas depois.

Para fins de comparação dos parâmetros de qualidade de água, são utilizados os parâmetros encontrados na resolução número 20 do Conselho Nacional do Meio Ambiente-CONAMA, para enquadramento dos rios e a portaria número 1469 do Ministério da Saúde para as fontes de abastecimento doméstico.

Em duas fontes de água utilizadas para o consumo humano (nascente abaixo de lavouras) foi avaliada a presença dos principais agrotóxicos utilizados nas regiões, mediante a coleta em recipiente de vidro e encaminhado ao Laboratório de Análises de Resíduos de Pesticidas do Departamento de Química da UFSM.

Como especificado, as quatro fontes que abastecem a maioria da população da localidade enquadra-se como área de cabeceiras, dando origem às nascentes de rios, cuja garantia da qualidade da água superficial irá depender da conservação das áreas nativas, principalmente nas encostas e topos sobre as nascentes. Em todas as fontes e pontos coletados, identifica-se, antes mesmo da amostra (via diagnostico), problemas de ordem a comprometer a qualidade da água (os quais foram descritos na caracterização dos pontos de coleta), tais como áreas não protegidas para entrada de animais, fossas e esterqueiras próximas a reservatórios e sangas e área sem cobertura vegetal entre meio e a montante da fonte.

Segundo portaria do Ministério da Saúde, não é permitido para águas destinadas ao consumo humano a presença de qualquer quantidade de Coliformes Totais, Coliformes Termotolerantes (coliformes fecais) e contagem de Bactérias Heterotróficas. Para a localidade estudada, a leitura das análises indica que nos pontos usados para satisfação humana, $80 \%$ não atende aos parâmetros legais exigidos, sendo imprópria para uso caso não sofram algum tipo de tratamento. Segundo a Portaria 518 (BRASIL, 2004), nas amostras procedentes de poços ou nascentes, a ocorrência de coliformes totais deve ter sua origem investigada e devem ser tomadas providências imediatas de caráter corretivo e preventivo, e então realizada nova análise.

Para as três análises realizadas fora da comunidade da Linha Jaques, a presença de Coliformes não traz surpresas, dado a percepção das relações que compõem e permeiam as regiões abrangentes. Para o interior do Parque, a fonte, por ser um ambiente aberto (tipo lagoa) e ser comum o relato de animais silvestres nas encostas e dentro do reservatório, a detecção torna-se um instrumento a reafirmar a necessidades de providências frente ao caso. Para a bacia do arroio Mairosa, em função da presença da área urbana de Derrubadas, que domina uma parcela significativa das suas nascentes, o aporte de esgotos sanitários e projeção de carga de coliformes derivado de animais atesta a fragilidade da sanga, o que é demonstrada pela análise. 
Relacionando os indicados para a bacia que envolve a comunidade da Linha Jaques, obtém-se que, para as quatro fontes de maior representatividade analisadas, três delas apresentam contaminação por Coliformes Totais, uma delas por Coliformes Totais e Fecais, uma porcentagem de $75 \%$ de fontes contaminadas e que, possivelmente, estará presente nas caixas de 25 famílias a jusante.

O caso mais problemático diz respeito à fonte Jaques 01 , com umas das maiores contagens para coliformes totais e de coliformes fecais, o que se justifica pela posição da fonte e pelos poucos cuidados atribuídos na sua preservação, como a entrada de animais sobre a área e pela pequena área com cobertura vegetal que moldura a fonte. A fonte localiza-se na meia encosta do morro, com uma extensa área de contribuição sobre lavouras mecanizadas, tornando-a suscetível em fortes precipitações, pelo rápido escoamento da água em direção à fonte desprotegida. É justamente por esse motivo que realizou-se, paralelamente, uma análise de agrotóxicos, cujos dados serão descritos adiante.

Os dados para esse ponto reforçam o quadro já notório para o poder público, que, segundo os laudos do Sistema de Informação de Vigilância da Qualidade da Água-SISAGUA para Consumo Humano - do Ministério da Saúde, os índices, desde 2006, sobre a fonte, indicam que para as dez análises realizadas até o referente ano todas apontam a presença de coliformes totais e fecais.

Para a fonte Jaques 02 , no período coletado, a análise não aponta a presença de nenhum micro-organismo patogênico, porém, traz ao momento a discussão feita por Copetti et al. (2009), sobre as fontes superficiais e a importância da limpeza dos reservatórios para evitar que as contaminações em períodos de chuva comprometam a qualidade da água nos demais períodos. Relata-se, também, que a distância da fonte em relação ao ponto de uso final, apesar de oportunizar a coleta de água na nascente, é um fator de interferência por permanecer dentro das tubulações por um período muito longo e em contato com o solo ou exposto ao aquecimento pelo sol, permite uma aceleração no crescimento bacteriano, quando presente (COPETTI, et al. 2009).

O uso de clorador, segundo técnico da Secretaria de Saúde do município ${ }^{5}$ é esporádico e, muitas vezes, a cargo dos próprios moradores e do agente de saúde da comunidade, o que não é relatado por nenhum agricultor nas entrevistas de campo.

Para as duas fontes de uso coletivo (Laste 01 e 02), a presença de coliformes totais classifica esse recurso como impróprio para o consumo das 12 famílias beneficiadas, caso não seja feito algum tipo de tratamento. Esses índices já foram anteriormente encontrados nas análises do SISAGUA, onde sete das oito coletas realizadas para a fonte apresentavam a presença de coliformes totais $\mathrm{e}$ fecais. O que é observado, também, para as duas fontes de uso individual, (fonte Maria Laste e Celso) que contém a presença de coliformes totais e fecais.

Segundo Copetti et al. (2009), as águas subterrâneas apresentam maior estabilidade da qualidade independente de eventos pluviométricos. No entanto,

\footnotetext{
${ }^{5}$ Em Entrevista com Jair Martens, funcionário responsável pelo monitoramento da qualidade da água dos poços semi-artesianos e fontes drenados do Município.
} 
seu uso se dá como uma forma de mascarar a realidade e como subterfúgio ao comprometimento em realizar atividades de forma a não comprometer a qualidade ambiental, principalmente das águas superficiais, além da falsa impressão que águas subterrâneas não apresentam problemas. Isso pelo fato da análise $n^{\circ} 10$, identificada como Sírio Simão BG, que retrata uma amostra coletada no poço semiartesiano da comunidade Barra Grande, apresentar contaminação com coliformes totais.

Os dados apresentados na tabela 03, para as duas sangas ( $n^{\circ} 9$ sanga Jaques e $\mathrm{n}^{\circ} 12$ sanga Fontana), aponta a presença de coliformes totais e fecais em maior proporção para a sanga Jaques, tendo, como hipótese, o maior número de moradores com banheiros tipo patente (casinha externa à casa na beira do córrego) e pela presença de maior atividades agropecuárias em sua extensão. Outro ponto que diferencia é a presença, na sanga Fontana, de corredeiras que, segundo Copetti et al. (2009) provocam o depuramento dos resíduos e oxigenação da água.

Do objetivo proposto para se identificar $\mathrm{pH}$, condutividade elétrica, cálcio total, magnésio total, ferro total, dureza total, amônia, nitrato, sólidos totais, a ocorrência de um erro de coleta, mais precisamente pelo tipo de embalagem utilizada, comprometeu e alterou os parâmetros de $\mathrm{pH}$, sódio, condutividade elétrica e sólidos totais, não sendo descritos no presente relatório. Para os demais parâmetros os índices estão abaixo do limite exigido pela Portaria do Ministério da Saúde e pelas resoluções do CONAMA.

\section{CONSIDERAÇÕES FINAIS}

A continuação do êxodo rural observado em anos anteriores para o Município de Derrubadas pode ser, em parte, explicada pela concentração de sua população em áreas rurais fragilizadas, de baixa aptidão agrícola para uso e limitada do ponto de vista produtivo e fundiário (na sua grande maioria minifundiários). Neste caso, serão os moradores de comunidades como essas, localizadas nas extremidades do município, os possíveis personagens a alimentar os dados negativos sobre o fluxo migratório do campo, às praças das cidades da região, e destas, para centros maiores.

Outra variável que contribui com esse processo se refere à qualidade de vida da população rural, onde o acesso a alguns bens e serviços se torna fundamental para estancar o fenômeno de esvaziamento dos espaços rurais. Para as análises da qualidade da água, praticamente todas as fontes se mantiveram fora dos padrões de potabilidade estabelecidos pelo Ministério da Saúde, principalmente pela presença de coliformes totais, onde a proteção física das fontes, construída pelos agricultores, não impede a entrada de poluentes que tornam a água imprópria para o consumo humano. Da mesma forma, a utilização do solo fora de sua capacidade de uso e a falta de planejamento paisagístico ambiental são evidências dos resultados dos altos níveis de contaminação. 
Associada à problemática da água, observa-se uma relação direta com o manejo dado aos esgotos domésticos da comunidade, que são lançados a céu aberto, ou em fossas convencionais próximos de nascentes e córregos, tornandose, segundo Copetti et al. (2009), fontes de poluição pontual e uma das principais fontes de poluição dos mananciais aquáticos no meio rural. Nesse caso, torna-se necessária a intervenção por parte dos gestores públicos locais para com o problema e a busca de soluções imediatas para mitigar seus efeitos ${ }^{6}$.

A alta declividade de seu território e sua proximidade com o rio Turvo e com o Parque Estadual do Turvo representa uma ameaça constante a outros ambientes, uma vez que a água canalizada na bacia, quando exposta a diferentes pressões como o identificado na pesquisa, tendem a rapidamente percorrer todo $o$ curso d'água, atingindo, em poucas horas, a foz do rio Turvo e, posteriormente, o rio Uruguai, ambos fora da comunidade.

Portanto, pela fragilidade e importância dada à água e ao solo da localidade estudada, torna-se urgente o uso de práticas de fácil aplicação, tais como: a preservação do entorno das fontes com uma faixa de vegetação natural, bem como seu isolamento para evitar a entrada de animais domésticos (gado e suínos); proteção e manutenção das fontes de uso individual; utilização de cloro para tratamento da água nas fontes e nas caixas de uso coletivo e individual; lavagem sistemática dos reservatórios de água; manutenção das canalizações; redução do uso de fertilizantes e agrotóxicos nessas áreas e áreas de risco (por meio do manejo integrado de praga; plantio direto sem herbicida, rotação de cultura, dentre outras), além de evitar o uso de fonte de água próximo de fossas, sumidouros e confinamento de animais?

Por fim, evidencia-se no trabalho que, mesmo possuindo uma grande dimensão de área preservada de mata atlântica (principalmente por abrigar a UC Parque Estadual do Turvo), aproximadamente com 50\% do território municipal coberto por uma vegetação nativa, as pressões sofridas pelos espaços adjacentes, na sua maioria, sob uso de uma agricultura convencional (inclusive pela comunidade estudada), tendem a comprometer a qualidade dos recursos naturais existentes e da própria saúde das famílias no meio rural.

Tal fenômeno reforça a teoria de que, apesar de suportar tal riqueza natural, a unidade de conservação se torna uma ilha de biodiversidade, isolada do cotidiano dos agricultores e criando barreiras políticas e morais, como retratado no próprio estudo do Plano de Manejo do Parque em 2005,

[...] No lado de dentro está a natureza, seus verdadeiros defensores, a ciência (em termos de verdade científica) e a lei (em termos de legislação preservacionista e conservacionista). No lado de fora estão os que possuem perfil oposto, os agressores do meio ambiente, o não saber em relação à área, os transgressores da lei e os que, moralmente, estão

\footnotetext{
${ }^{6}$ Baseado nos trabalhos de Copetti et al. (2009), sugere-se, aliado a outras práticas agronômicas e ambientalmente sustentáveis, a apropriação de tecnologias alternativas para tratamento de efluentes como o sistema de tratamento por zona de raízes.

7 Práticas similares foram sugeridas pelo Relatório sobre qualidade de água, do projeto de monitoramento ambiental de microbacias hidrográficas do programa RS - Rural.
} 
preocupados apenas com a satisfação de seus interesses imediatos de obtenção de riqueza". SEMA (2005).

\section{REFERÊNCIAS}

BRASIL. Ministério do Planejamento, Orçamento e Gestão. Instituto Brasileiro de Geografia e Estatística. Contagem Populacional. Disponível em: <http://www.sidra.ibge.gov.br/bda/popul/> Acesso em: jan. 2009.

COPETTI, A. C. et al. Proteção de fontes superficiais e qualidade da água para consumo humano numa pequena bacia hidrográfica. In: XXXII CONGRESSO BRASILEIRO DE CIÊNCIA DO SOLO, 32., Fortaleza. Anais... Fortaleza: SBCS, 2009.

DUFUMIER, M. Les projets de développement agricole: Manual d'expertise. Paris: Ed. Khartala/CTA, 1996.

GARCIA FILHO, D. P. Análise Diagnóstico de Sistemas Agrários: Guia Metodológico. Brasília: INCRA/FAO, 2001.

INPE - Instituto Nacional de Pesquisas Espaciais. Departamento de Processamento de Imagens. (INPE/DPI). Sistema de Processamento de Informações Georreferenciadas (SPRING v. 5.02), 2008. Disponível em: <http://www.inpe.br/spring >. Acesso em: 5 ago. 2009.

MAZOYER, M.; ROUDART, L. História das agriculturas do mundo. Lisboa: Instituto Piaget, 2001.520p

RHEINHEIMER, D.S. (Ed.). Caracterização física, química e biológica dos solos na microbacia hidrográfica do Arroio Lino, Nova Boemia: Agudo, Ano II. 2003. 115p

RHEINHEIMER, D.S. et al. Aspectos quanti-qualitativos relacionados aos sedimentos e a água numa pequena bacia hidrográfica ocupada por agricultores assentados pela reforma agrária. Projeto MCT/CNPq/CT-AGRONEGÓCIO/CTHIDRO, n 27/2008, Santa Maria, 2008.

RIO GRANDE DO SUL. Secretaria Estadual do Meio Ambiente. Departamento de Recursos Hídricos. Relatório anual sobre a situação dos recursos hídricos no Estado do Rio Grande do Sul. Ed. 2007/2008. Porto Alegre, dez. de 2008.

Secretaria Estadual do Meio Ambiente. Departamento de Florestas e Áreas Protegidas. Plano de Manejo do Parque Estadual do Turvo. Porto Alegre, 2005. 354p. Disponível em $<$ http://www.sema.rs.gov.br/upload/Plano_manejo_PETurvo.pdf>. Acesso em: dez. de 2009. 
TRENNEPOHL, D; MACAGNAN, R. Impactos ambientais da dinâmica de desenvolvimento da região noroeste colonial do Rio Grande do Sul. Revista Brasileira de Gestão e Desenvolvimento Regional. São Paulo, v. 4, n. 1, p. 195220, jan. 2008.

Submetido em

Aprovado em

\section{Sobre os autores}

\section{Dhonathã Santo Rigo}

Mestre em Extensão Rural pela Universidade Federal de Santa Maria, UFSM (2012). Extensionista Rural da EMATER/ASCAR (Associação Riograndense de Empreendimentos de Assistência Técnica e Extensão Rural).

Endereço: EMATER/ASCAR - Av. Ipiranga 715, Centro. 98760-000 - Chiapetta - RS - Brasil.

E-mail: rigoufsm@gmail.com e/ou emchpeta@emater.tche.br

\section{Pedro Selvino Neumann}

Doutor em Engenharia de Produção pela Universidade Federal de Santa Catarina (2003). Professor Adjunto da Universidade Federal de Santa Maria.

Endereço: Cidade Universitária - RST 287, Km 9, Camobi. 97900-119 - Santa Maria - RS - Brasil. E-mail: psneuman@ccr.ufsm.br

\section{Paulo Roberto Cardoso da Silveira}

Doutor pelo Programa Interdisciplinar em Ciência Humanas da Universidade Federal de Santa Catarina (2010). Professor Assistente da Universidade Federal de Santa Maria.

Endereço: Cidade Universitária - RST 287, Km 9, Camobi. 97900-119 - Santa Maria - RS - Brasil. E-mail: silveira@ccr.ufsm.br 